\title{
Runflat Sisteminin Dinamik Analizi
}

\author{
Cihan PAMUK ${ }^{a}$, Ulvi ŞEKER ${ }^{b}$ ve Ali KALYON ${ }^{*}$
}

${ }^{a}$ Karabük Üniversitesi, Fen Bilimleri Enstitüsü, Imalat Mühendisliği Bölümü, Karabük, Türkiye

${ }^{b}$ Gazi Üniversitesi, Teknoloji Fakültesi, Imalat Mühendisliği Bölümü, Ankara, Türkiye

${ }^{c}$ Karabük Üniversitesi, Teknoloji Fakültesi, Imalat Mühendisliği Bölümü, Karabük, Türkiye

Öz

Runflat sistemi araç lastiğinin patladıktan sonra güvenli olarak yol almasını sağlayan sistemlerin başında yer almaktadır. Runflat sistemi olmayan araçlar lastik patladıktan sonra hareket kabiliyetini kaybetmektedirler. Runflat sistemi genel olarak askeri alanda kullanılmakla beraber ambulans, itfaiye, toplu taşıma ve sivil araçlarda da kullanılmaktadır. Bu çalışma kapsamında Runflat sisteminde kullanılan kestamid (PA06) malzemesin mekanik özellikleri baz alınarak sonlu elemanlar yöntemiyle dinamik analizi yapılmıştır. Analiz çalışmasında Toma aracında kullanılan 22,5" jant modeline uygun olan Runflat sistemi esas alınmıştır. Araç toplam ağırlığı göz önünde bulundurularak Runflat başına düşen 49050 Newton (N) yük uygulaması ile analiz çalışmaları yapılmıştır. Dinamik analiz çalışmaları aracın $50 \mathrm{~km} / \mathrm{h}$ hızla yol alırken taşa çarpması ve çukura çarpması göz önünde bulundurularak yapılmıştır. Analiz çalışmaları sonucunda Runflat sisteminin taşa ilk çarpma anında toplam gerilme değeri maksimum 51,195 $\mathrm{MPa}$ olarak bulunmuştur. Runflat sisteminin çukura ilk çarpma anında toplam gerilme değeri maksimum 51,197 MPa olarak elde edilmiştir.

Anahtar Kelimeler: Runflat sistemi, sonlu elemanlar analizi, dinamik analiz.

\section{Dynamic Analysis of the Runflat System}

\section{Abstract}

Runflat system is the primary system which allows safe travel after the blowout of the vehicle tire. The vehicles which don't have Runflat system lose their mobility after the tire blow-out. Runflat system generally used for military field. They are also used for ambulances, fire trucks, public service vehicles and civilian vehicles. In this study, mechanical properties of kestamid (PA06) material used in Runflat system base dynamic analysis was done by using finite elements method. The study is based on 22,5" rim model Runflat system of Toma vehicle. The results were obtained by the force application of 49050 Newton $(\mathrm{N})$ on each Runflat system bearing in mind the total weight of vehicle. In the dynamic analysis, when the vehicle was traveling at a speed of $50 \mathrm{~km} / \mathrm{h}$, it was made by striking the stone and crashing into the pit. As a result of dynamic analysis, maximum strain value of the Runflat system at the first impact was found to be 51,195 MPa. Total maximum strain value was found to be 51,197 MPa at the moment of first impact with pit.

Keywords: Runflat system, finite element analysis, dynamic analysis.

\footnotetext{
${ }^{*}$ Sorumlu Yazar: ORCID ID: orcid.org/0000-0003-3300-1336

e-mail: alikalyon@karabuk.edu.tr
}

Received: 03.12.2019

Accepted: 11.02.2020 


\section{Giriş}

Runflat (RFT) sistemi ilk olarak 1926 yılında Hutchinson firması tarafindan askeri ve güvenlik araçları için geliştirilmiştir. Hutchinson firması taktik Runflat, Variable Function Insert (VFI) Runflat ve Countermine VFI olarak üretim yapmıştır. Runflat, dünya üzerinde askerler tarafından tüm arazi koşulların da ve savaş durumlarında hareketlilik ve güvenlik sağlamak için üretilmiştir. Countermine VFI Mayın patlamasında askeri personelin hayatta kalabilmesini ve korumayı artırmak için özel olarak tasarlamıştır [1]. Askeri araçlar muhabereler de hareketliliğini garantilemek ana sorunların başında yer almaktadır. Yapılan çalışmalarda dolgu lastik olarak üretim yapılması, lastik hasarının minimum seviyeye indirilmesi amaçlanmıştır. Muhabereler de meydana gelen silahlı saldırı, mayın veya geliştirilmiş patlayıcı alet Improvised Explosive Device (IED) üzerinden geçerek zarar görebilmektedir. İlk tekerlekli askeri araçlar İkinci Dünya Savaşı kadar erken bir zamanda kullanılmaya başlanmıştır [2].

Başlangıçta dolgu lastik olarak kullanılan sistemin dezavantajları mevcuttur; sürüş konforu, yol tutuşu, hız, hızlı manevra yeteneği ve aşınma direnci standartlarının koşullarda dahil olmak üzere başarısız olmuştur. Son yıllar da geliştirilen sistemler sayesinde araçların daha hızlı hareket edebilmesi ve daha güvenli hareket edebilmelerine olanak sağlayabilmektedir. Teknolojinin gelişmesi ile birlikte farklı ülkeler de farklı Runflat sistemleri üzerine çalışmalar yapılarak gelişmeler meydana gelmektedir. Runflat, lastik patlayarak indiğinde güvenli olarak sürüş yapabilmemizi sağlayan geleceğin sistemidir. Runflat sisteminin temel konsepti, lastik patlak halde bile 80 $\mathrm{km} /$ saat'lik maksimum hız ile sürüş yapabilmesidir. Runflat sisteminin diğer adı patlak lastik yürütücü sistem olarak da belirtilmektedir. [3].

Literatürdeki sınırlı sayıdaki çalışmalarda mühendislik ve tasarım alanında çeşitli senaryolar altında Runflatları geliştirmek için uygulamalar yapılmıştır. Pamuk ve arkadaşları çalışmalarında Runflat sisteminin statik analizini sonlu elemanlar yöntemi kullanarak yapmıştır. Çalışmalarının sonucunda jant iç yüzeyine uygun tasarlanan Runflat formunun iç yanak kısımlarında maksimum gerilme ve maksimum deformasyonun oluştuğunu belirlemişlerdir [4]. Diğer çalışmalarda optimizasyon teorisi, mühendislik ve tasarım uygulamaları için kullanılmıştır. $\mathrm{Bu}$ durum mühendislerin ihtiyaç duydukları çözümler ve tasarım problemleri için geniş 
bir tasarım havuzundan faydalanabilmelerine olanak sağlamıştır [5]. Optimizasyon yöntemi, tasarım değişkenlerine göre üç tipe ayrılmaktadır. Bunlar boyut optimizasyonu, şekil optimizasyonu ve topoloji optimizasyonudur [6]. Zor koşullar altında kurşun geçirmez lastik için yüksek performans gereksinimlerden dolay1 mevcut Runflat modelleri tasarım gereksinimlerini karşılayamamaktadır. $\mathrm{Bu}$ nedenle birçok çalışmada sonlu elemanlar yöntemleri kullanılarak Runflat lastikler için topoloji optimzasyonu çalışmaları yapılmıştır [7-9]. Yapılan bu çalışmalarda, Runflat için destek yapıları başarılı bir şekilde optimize edilmiştir. Ancak tasarımcıların optimizasyon çalışması sonrası doğrulama amacıyla modeli yeniden oluşturması için gereken en uygun yapıyı elde etmesi uzun süreler almaktadır [10].

Runflat sisteminin avantajları şu şekilde özetlenebilir. Runflat ile yedek lastik ihtiyacına gerek kalmaz. Yüksek güvenlik gerektiren durumlarda zirhlı araçların lastiği patladığında jant Runflat üzerine oturarak aracın olay yerinden hızlı bir şekilde uzaklaşmasına yardımcı olmaktadır. İtfaiye araçlarının olaya giderken lastiğinin patlaması durumunda zaman kaybı yaşamadan aracın yangına k1sa sürede müdahale edebilmesine yardımcı olmaktadır. Ambulans araçlarında hasta nakli sırasında, olası bir lastik patlamas1 durumunda devreye girerek hastanın ivedi bir şekilde ilgili sağlık merkezine ulaştırmasını sağlar. Lastik patladığında jantın zeminle temasını önleyerek direksiyon hakimiyetinin kaybedilmesini önlemektedir. Jantın sürtünmeden kaynaklı jant üzerinde oluşabilecek hasarları engellemektedir. Araçların donma sıcaklığında etkin olarak kullanılır, her türlü dış etkiye karşı lastiğin korumasını artırır [11]. $\mathrm{Bu}$ çalışmanın amacı Runflat sisteminin maruz kaldığ 1 yüklerden kaynaklı oluşan problemlerin sonlu elemanlar yöntemiyle modellenmesi ve analiz edilmesidir. Dinamik analiz çalışması kapsamında hareket halinde giderken taşa ve çukura temas etmesinden kaynaklı gerilme değerleri incelenmiştir.

\section{Materyal ve Metot}

Bu çalışmada 22,5” jant modeline uygun Runflat sistemi üzerinde sonlu elemanlar metodu kullanılarak analiz çalışması yapılmıştır. Analiz kapsamında ANSYS yazılımının Workbench modülünde gerçekleştirilmiştir.

\section{Runflat Sistemi Geometrisi}

Runflat sistemi toplumsal olaylarda kullanılan toma arac1 22,5" jant ebatına uygun model üzerinde analiz yapılmıştır. Runflat sisteminin 3 boyutlu katı modeli 
Solidworks programında tasarlanmıştır. ANSYS 18.2 programına aktarılmıştır. Tasarlanmış olan katı model Şekil 1'de Runflat sistemi 3 boyutlu tasarımdan gösterilmektedir. Şekil 2'de Runflat üretime geçme aşamasında ANSYS sisteminin jant üzerinde montajlı hali yardımıyla yapısal analize tabi gösterilmektedir. 3 boyutlu katı model tutulmaktadır.

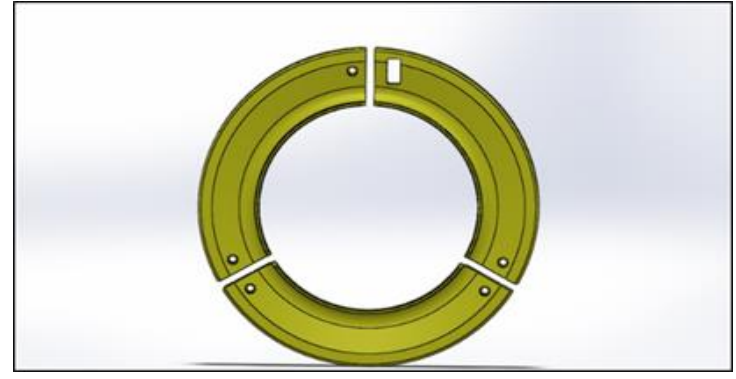

Şekil 1. Runflat sistemi

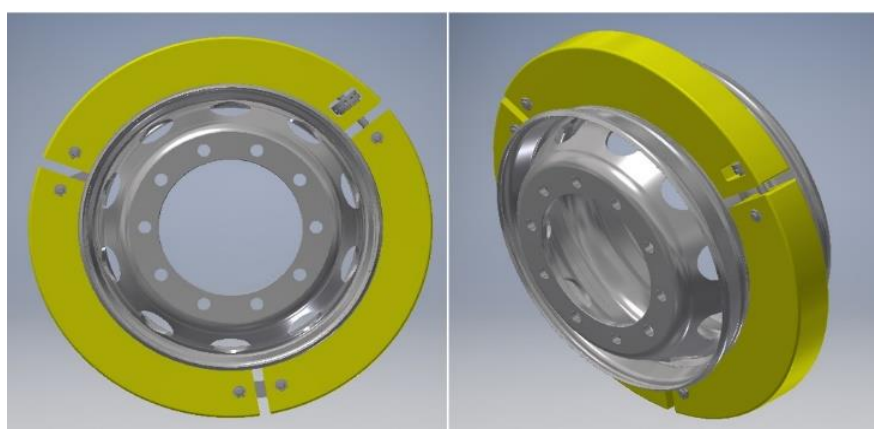

Şekil 2. Runflat sisteminin montajı

\section{Runflat Malzeme Seçimi}

Runflat sisteminin analizinde Naylon PA06 olarak adlandırılan ve sanayi alanında Kestamid olarak nitelendirilen malzemenin özellikleri ele alınarak analiz işlemleri yapılmıştır. Naylon 6, döküme gelen bir yapıdadır. Diğer malzemeler zor aktığından yüksek basınç gerektiren enjeksiyon ve ekstrüzyon yöntemlerini kullanmaktadırlar. İyi mekanik ve tribolojik özelliklere sahip olan naylon dişli çark, kam, kaymalı yatak malzemesi olarak kullanılmaktadır [12]. Mevcut çalıșma kapsamında kullanılan malzeme değerleri Tablo 1'de gösterilmiştir. Kestamid üretimi yapılırken her firma mekanik özellikleri üzerinde değişikler yapabilmektedir. Kestamid döküm proseslerine farklı kimyasal ürünler eklenerek sertlik değeri düşürülebilmektedir. Su emme özelliğine sahip olması nedeniyle nemli ortamlarda bulundurularak mekanik özelliklerinin değişim göstermesine neden olmaktadır. 
Tablo 1. Kestamid PA06 malzemesine ait mekanik özellikleri [13]

\begin{tabular}{|c|c|}
\hline ÖzgülĂ̆gırlık (gr/cm³) & 1.15 \\
\hline Su Emme (Doymuş) (\%) & 7 \\
\hline Çekme dayanımı $\left(\mathrm{Kg} / \mathrm{cm}^{2}\right)$ & 850 \\
\hline Elastik Modülü(MPa) & 4000 \\
\hline Kopma Uzaması (\%) & $>20$ \\
\hline Basma Dayanımı $\left(\mathrm{Kg} / \mathrm{cm}^{2}\right)$ & 950 \\
\hline Basma Modülü (MPa) & 2700 \\
\hline Darbe Dayanımı $\left(\mathrm{Kj} / \mathrm{m}^{2}\right)$ & 5.6 \\
\hline Sürtünme Katsayısı(Dinamik) & 0.39 \\
\hline Sertlik (Shore D) & 84 \\
\hline Aşınma Hızı (mg/km) & 0.44 \\
\hline K Faktörü $\left(\mathrm{mm}^{3} / \mathrm{Nm}\right)$ & $5.0 \times 10^{-6}$ \\
\hline Elastisite Modülü & $2000-3500$ \\
\hline Sıcaklık Sinırı & 82 \\
\hline
\end{tabular}

\section{Runflat Sistemi için Mesh Oluşturma}

Şekil 3' de tasarımı yapılan Runflat sistemi üzerine genel yapısal ağların atılmas1 görüntüsü verilmiştir. Genel yapısal ağların yanı sira kuvvetin uygulandığı yüzey alanına daha doğru sonuçlar yakalamak için kuvvete maruz kalan kısma daha yoğun yapısal ağlar ile örülmüştür. Runflat sisteminin geneline mesh uygulaması kapsamında 76.545 adet düğüm ile 43.352 adet ağ elemanı yardımıyla örülmüştür. Yapısal ağların genel olarak örülmesinin yanında kuvvete maruz kalan bölgeye daha yoğun yapısal ağ örülmüştür. Özellikle jant kısmını saran iç yanak bölgesi en fazla yüke maruz kalmaktadır. Kuvvette maruz kalan bölgenin daha doğru sonuçlar elde edilmesi açısından yapısal ağların yoğun olması önemlidir.

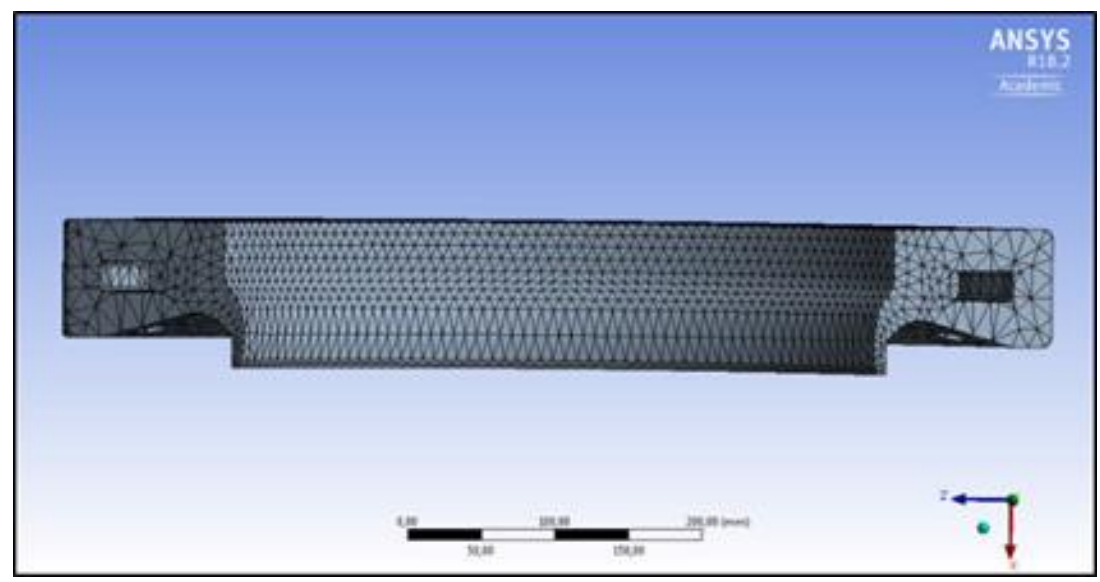

Şekil 3. Kuvvetin geldiği yüzeydeki yapısal ă̆ görüntüsü 


\section{Runflat Sistemine Uygulanan Yükler}

Runflat sistemine yapısal ağların örülmesinin ardından kuvvet faktörünün uygulanması yapılmıştır. Tablo 2'de toma aracının ağırlık yükleri dikkate alınmıştır. Aracın genel ağırlığı ile su alma kapasitesi göz önünde bulundurularak teker başına düşen ağırlık miktarı belirlenmiştir. Aracın tekerlek başına düşen ortalama ağırlık 5 ton olarak ele alınmıştır. Kuvvet uygulamasında 5 tona karşılık $49050 \mathrm{~N}$ 'luk kuvvet uygulaması yapılmıştır (Şekil 4).

Tablo 2. Toma aracı jant ebadı ve ağırlık oranlarl [14]

\begin{tabular}{|c|c|}
\hline Jant Ebadı & 22,5 inç \\
\hline Araç A ğırlık Oranı & 15 Ton \\
\hline Su Tank Kapasitesi & 5000 Litre \\
\hline
\end{tabular}

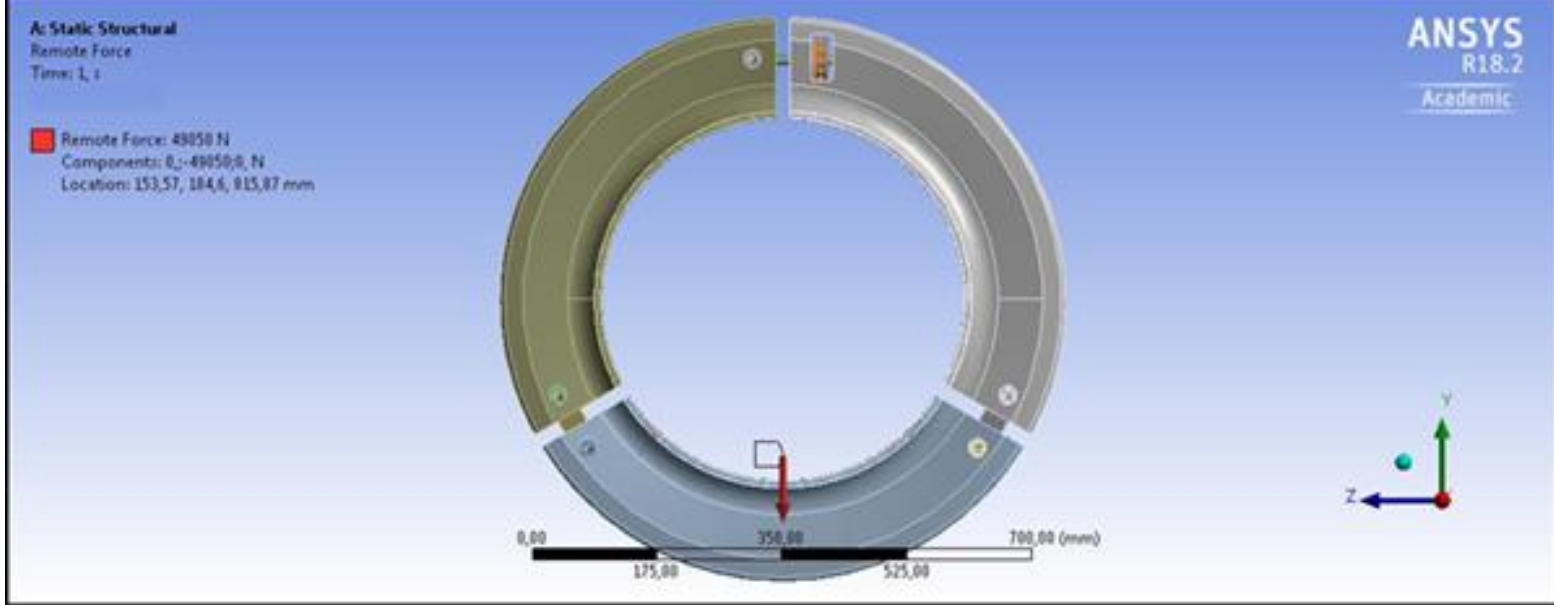

Şekil 4. Kuvvetin bölgeye uygulanması.

\section{Deneysel Sonuçlar ve Tartışma}

Sonlu elemanlar analiz yöntemi kullanılarak Runflat sistemi üzerinde dinamik analiz çalışması yapılmıştır. Araç yol alırken Runflat sistemine risk yaratabilecek durumlar göz önünde bulundurulmuştur. Risk olarak Runflat sisteminin taşa çarpması ve çukura çarpmasından kaynaklanan durumlar üzerinde analiz yapılmıştır. Modellenen
Runflat sisteminde bağlantı elemanları tasarımdan çıkarılarak sadeleştirmeye gidilmiştir. Modellemede Runflat sistemi tek parça olarak tasarlanmıştır. Runflat sistemi genel test standartlarına uygun olarak $50 \mathrm{~km} / \mathrm{h}$ ile $50 \mathrm{~km}$ mesafe gitmesi gerekmektedir [15]. Yapılan analizde Runflat sitemine düşen yük 49050 N olarak girilmiştir. İlk olarak araç $50 \mathrm{~km} / \mathrm{s}$ hızla yol alırken taşa çarpma analizi yapılmıştır. 
Kullanılan taş modeli arazide risk oluşturabilecek keskin köşeli yapı olarak ele alınmıştır. Taşın tasarımının oluşturulmasında Runflat genişliği göz önünde bulundurulmuştur. Taşın ebatları Runflat genişliğinden daha büyük tasarlanmıştır. İkinci olarak araç $50 \mathrm{~km} / \mathrm{h}$ hızla yol alırken çukura çarpması analizi yapılmıştır. Kullanılan çukur modeli arazide risk oluşturabilecek keskin köşeli ve derin yapı olarak ele alınmıştır. Çukurun tasarımının oluşturulmasında Runflat genişliği göz önünde bulundurulmuştur. Çukur ebatlarının Runflat genişliğginden daha büyük tasarlanmıştır.

Runflat sistemine göre yapılan analiz kapsamında taşa ve çukura temas ettiği anda en yüksek gerilme değerleri ortaya çıkmaktadır. Yapılan analiz çalışmasında taşa ilk çarpmasında oluşan maksimum gerilme değeri Şekil 5'te gösterilmektedir.

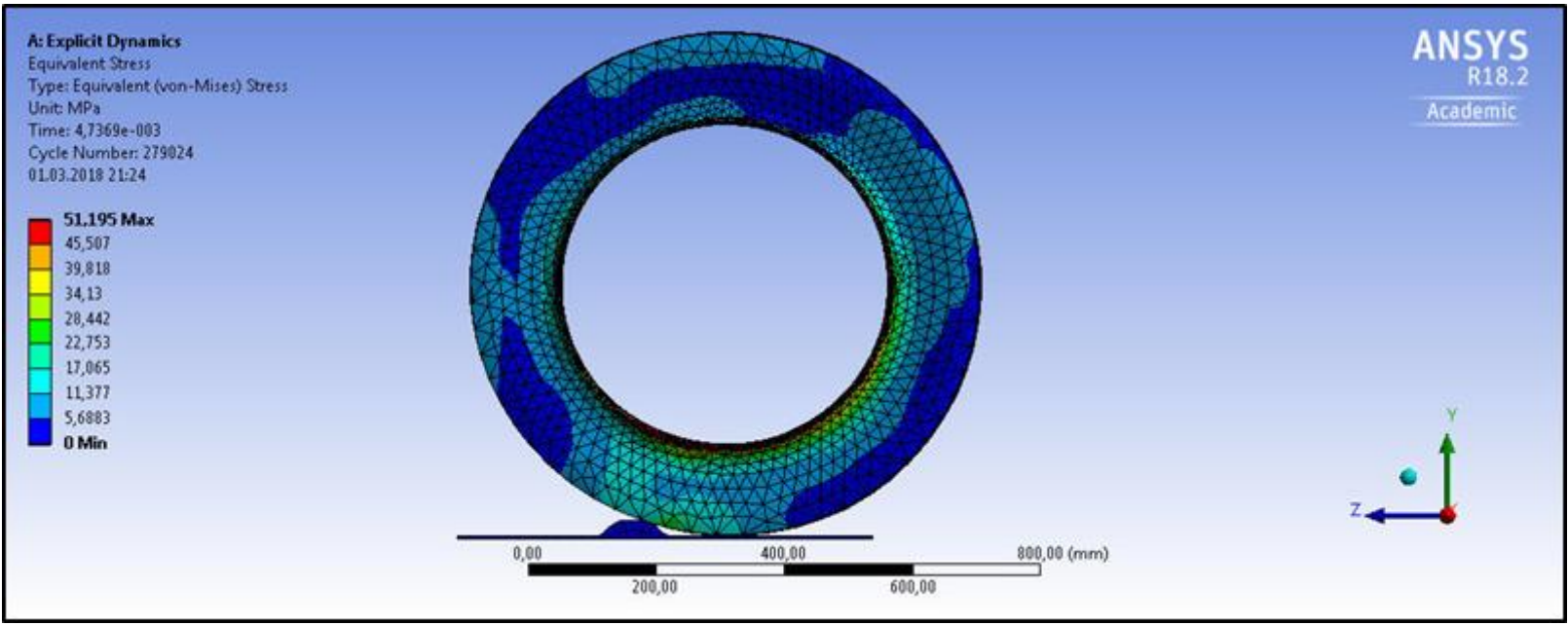

Şekil 5. Runflat sisteminin taşa çarpması.

Runflat sistemi yolda giderken herhangi bir sert nesneye temas etmesi bölgesel olarak basınca maruz kalmasına neden olmaktadır. Özellikle askeri araçlarda kullanılan sistem arazi şartlarında kullanılmaktadır. Arazide çok fazla keskin köşeli taşlardan kaynaklı riskler tespit edilmiştir. Dinamik analiz aşamasında Runflat sisteminin ilk taşa temas etmesi esnasında maksimum gerilme değeri ortaya çıkmaktadır. Runflat sisteminin $50 \mathrm{~km} / \mathrm{h}$ yol alırken taşa çarpmasıyla maksimum gerilme değeri 51.195 MPa çıkmaktadır.

Runflat sisteminin taşa temas ettiği anda oluşan gerilme değerleri iç yanak kısmında meydana gelmektedir. Runflat iç yanak kısmına yükün en fazla düştüğü yer olduğundan darbe esnasında da basincin artmasına sebep olmaktadır. Araç hareket halindeyken taşa çarpması veya taşın 
üzerinden geçmesi Runflat üzerindeki sistemi altında kalması maksimum gerilme basınç değerini etkilemektedir. Runflat değerinin aynı oranda kaldığı Şekil 6'da sistemine taşın ilk çarpmasıyla oluşan gösterilmektedir maksimum gerilme değeri ile taşın Runflat

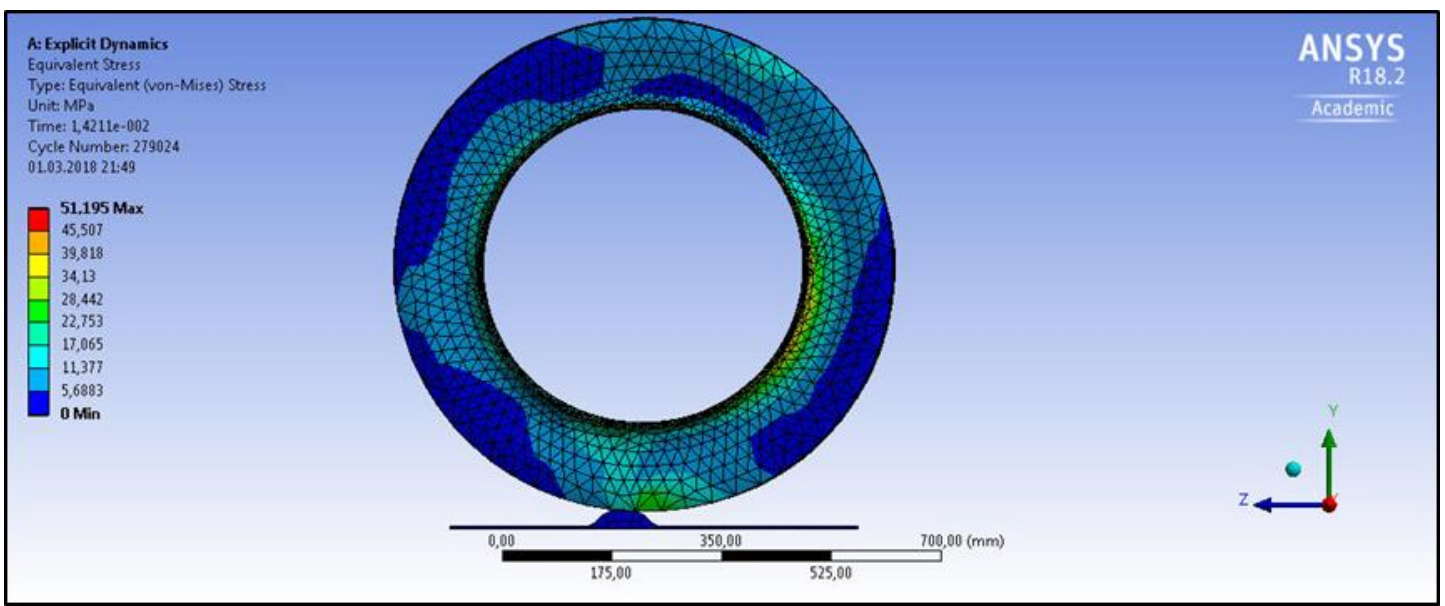

Şekil 6. Taşın Runflat sistemine tam olarak temas etmesi.

Runflat sisteminin tașa ilk çarpması ve taşın Runflat sisteminin altında kaldığı durumlar da maksimum gerilme değeri ince kısımlarda çıkmaktadır. Runflat sisteminin janta uygun olarak tasarlanmasiyla kaynaklanmaktadır. Jant yapısına uygun tasarlanan sistemde yanak kısmının ince kalması yük karşısındaki direncinin zayıf olmasına sebep olmaktadır. Yanak kısmının zayıf olması $51.195 \mathrm{MPa}$ gerilme yüküne maruz kalmaktadır (Şekil 7).

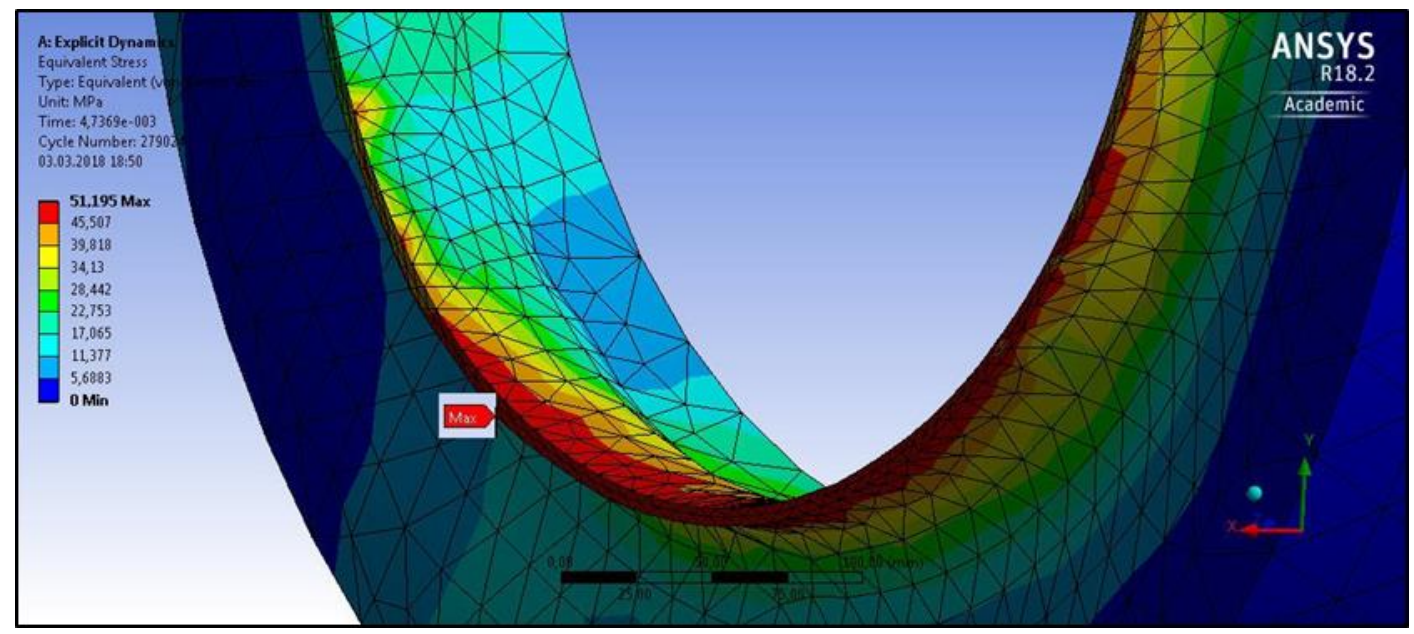

Şekil 7. Runflat sisteminin taşa çarpma esnasında maksimum gerilme değeri 
Runflat sisteminin taşa çarpması ve üzerinden geçmesi esnasında maksimum gerilme değerinin ince yanak kısmında çıktığı görülmektedir. Her iki darbe anında basınç değerinin sabit olarak kalması iç yanak yüzeyinde çıkması jant formuna uygun tasarımdan kaynaklıdır. Araç seyir halindeyken Runflat sisteminin darbelere maruz kalması ince kenar kısmında olmaktadır. İnce yanak kısımlarında oluşan hasardan kaynaklı Runflat sisteminin devam etmesine engel olmamaktadır.

$$
\text { Runflat sisteminin araç seyir }
$$
halindeyken çukura girmesi esnasında oluşabilecek risklere karşı dinamik analizi yapılmıştır. Şekil 8'de Runflat sisteminin çukura ilk çarpma anında en yüksek gerilmenin meydana geldiği görülmektedir. çatlamalara ve kırılmalara sebep

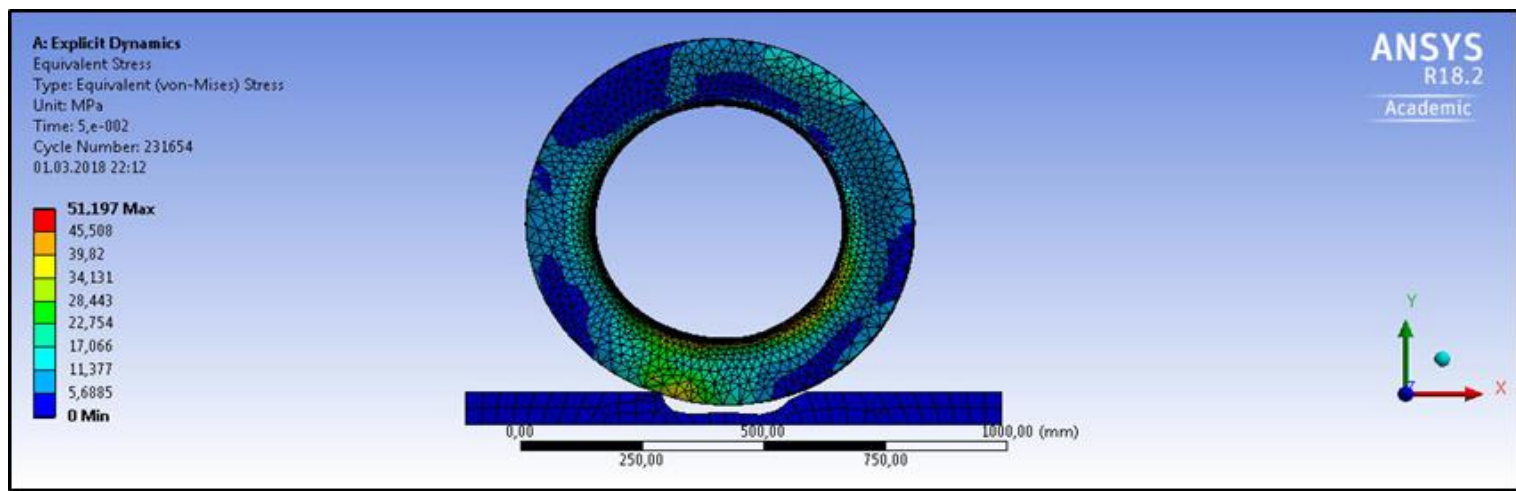

Şekil 8. Runflat sisteminin çukura çarpmast.

Runflat sisteminin çukura sisteminin ince kenarlarında maksimum çarpmasından kaynaklanan maksimum gerilme bölgesi taşa çarpma noktasındaki maksimum gerilme bölgesiyle aynıdır. Jantın formunu uygun tasarlanan Runflat gerilme görülmektedir. Şekil 9'da Runflat sisteminin çukura çarpmasında maksimum gerilme $\quad 51.197 \quad$ Mpa bulunduğu gösterilmektedir.

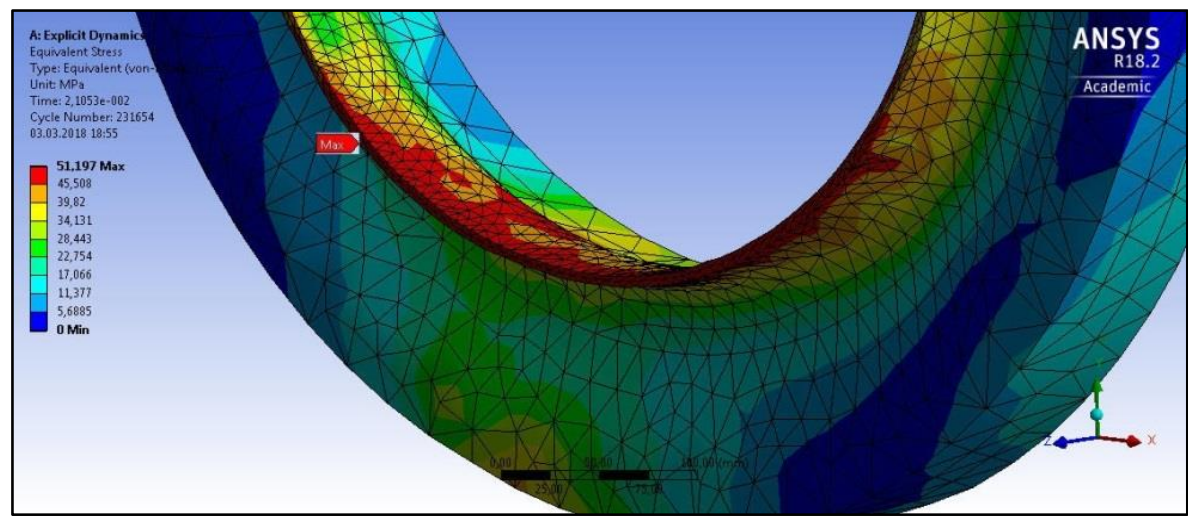

Şekil 9. Runflat sisteminin çukura çarpma esnasında maksimum gerilme değeri. 
Çukura temas ettiği anda maksimum gerilme kuvveti ortaya çıkmaktadır. Jant kısmına oturan iç yanak yüzeyinin ince kenarında maksimum gerilme değeri elde edilmiştir. Yapılan analiz çalışmasında genel olarak ince kenardan kaynaklı problemler ortaya çıkmaktadır. Statik analiz kısmında ve dinamik analiz kısmında elde edilen sonuçlara bakıldığında iç yanak yüzeyinin ince yanak kısmında deformasyonlar görülmektedir. Yapılan analizlerde taşa ve çukura çarpmasında en yüksek gerilme değerleri eşit çıkmaktadır. Runflat sisteminin taşa ilk çarpma anında maksimum 51.195 MPa, çukura çarpma anında $51.197 \mathrm{MPa}$ değerleri ortaya çıkmaktadır. Tablo 3' te dinamik analiz incelemelerinin sonuçları gösterilmektedir.

Tablo 3. Dinamik analiz sonuçları.

\begin{tabular}{|c|c|c|}
\hline Araç Hızı & Darbe Şekli & Maksimum Gerime Değeri \\
\hline $50 \mathrm{~km} / \mathrm{h}$ & Taş & $51.195 \mathrm{MPa}$ \\
\hline $50 \mathrm{~km} / \mathrm{h}$ & Çukur & $51.197 \mathrm{MPa}$ \\
\hline
\end{tabular}

Runflat sisteminin statik ve dinamik analiz altındaki davranışlarını konusu üzerinde atıf yapılabilecek kaynak bulunamamıştır. Runflat sistemleri alanında yapılan çalışmalar güvenlik nedenleri ile kısıtlı ve yayınlanmasına izin verilmeyen bulgulardır. Var olan deneysel ve analiz sonuçlarına bu çalışmada atıf yapılamamıștır. $\mathrm{Bu}$ durumdan ötürü deneysel çalışma sonuçlarıyla ilgili kaynaklarla ilişkisi değerlendirilememiştir.

\section{Sonuçlar}

Toma aracina takılan 22,5" jant modeline uygun Runflat sistemi üzerinde dinamik analizi gerçekleştirilen bu çalışmada araç seyir halinde giderken taşa ve çukura çarpmasından kaynaklı oluşabilecek riskler üzerinde sonlu elemanlar yöntemi kullanılarak modelleme yapılmıştır. Taşa ve çukura çarpmasından kaynaklı maksimum gerilme değerleri eşit bulunmuştur. Runflat sisteminde en fazla gerilme değerleri iç yanak kısmında olduğu hesaplanmıştır. İç yanak kısmında oluşan gerilme yüklerinden dolayı ufak çatlaklar ve kırılmalar olabilmektedir. İç yanak kısmında meydana gelen çatlamalar ve kırılmalar sistemin çalışmasına engel olmayacak düzeyde ve düşük seviyede oluşmaktadır. Dinamik analiz çalışmasında elde edilen sonuçlar Runflat sisteminin analizi yapılan olumsuz koşullar altında sürüşünü devam ettirebileceğini göstermektedir. Çalışma sonucunda Runflat sisteminin dayanıklılığı ve güvenirliliği 
sonlu elemanlar yöntemiyle desteklenmiştir.

\section{Kaynaklar}

[1] İnternet: Hutchinson, "Military Tactical Runflats" 2017. http://www.hutchinsoninc.com/CMS/index .php?page=Tactical_Runflats.

[2] Ejsmont, J., Stryjek, P., Nikisz, T. And Omyliński, K. 2015 .Innovatıve Runflat Systems" Journal of KONES Powertrainand Transport, 22 (1): 299-306.

[3] Karaman, F., 2014. 22,5" Jantlar İçin (3) Parça Run Flat (Patlak Gider) Sökme Takma Makinesi Tasarımı. Mühendis ve Makina, 55( 654): 30-34.

[4] Pamuk, C., Şeker, U., Kalyon, A 2018 Runflat sisteminin statik analizi. 1st International Eurasian Conference on Science, Engineering and Technology, 911916

[5] Joshua, D.D., Ramana, V.G 2014. A survey of structural and multidisciplinary continuum topology Optimization: post 2000. Struct Multidiscip Optim. 49:1-38

[6] Noilublao, C., Bureerat, S 2009. Simultaneous topology shape and sizeing Optimization of skeletal structures using multi-objective evolutionary algorithms. Dos Santos WP Evolutionary Computation, 24: 487-508

[7] Yang, X., Tong, J., Zhang, F., Zhang S.J 2006. Application of self adaptive virtual design to run-flat insertion. Journal of Jinlin Univesity 36:705-709.

[8] Li, L., Hu, L.C., Shao, P.L. 2008 Design and analysis of a new tire. Journal of Engineering Design 15:220-224
[9] Zhao, H.R 2012 Research on Inner Support Runflat Tire System in Low Pressure. Yüksek Lisans Tezi, Harbin Mühensdislik Fakültesi

[10] Guan, Z., Zheng-Dong, M., Aiguo, C., Guangyao, L., Jin, H 2015. Design Optimization of a Runflat structure based on multi-objective genetic algorithm. Struct Multidisc Optim 51:1363-1371.

[11] Pamuk, C. 2018. Runflat Sistemlerinin Analizi, Fen Bilimleri Enstitüsü, Karabük Üniversitesi, Karabük.

[12] İnternet: Balıkesir Üniversitesi, Termoplastik ve Termoset Plastikler. 2016. http://w3.balikesir.edu.tr/ ay/lectures/pm/p lastikte.mek2.pdf.

[13] İnternet: Polimer ve Kimya Sanayi A.Ş., " Kestamid Grubu Teknik Değerler Tablosu",http://www.polikim.com.tr/kesta middatasheet_tr.pdf (2017).

[14] İnternet: Nurol Makine.2018. Ejder Toma",http://www.nurolmakina.com.tr/tr/u runler/ejder-toma.

[15] Kuerten, D. 1988. Run-Flat Tires, Proceedings Annual Reliability And Maintainability Symposium, 62-67. 